\title{
EFFECTS OF CINNAMON EXTRACT SUPPLEMENTATION ON CREATINE KINASE ACTIVITY IN BADMINTON ATHLETES
}

original paper

(1) University School of Physical Education in Wroclaw

DOI: https://doi.org/10.5114/hm.2020.94196

\section{JUNAIDI JUNAIDI ${ }^{1}$, TOMMY APRIANTONO ${ }^{2}$, BAGUS WINATA ${ }^{2}$, FAHMI HASAN ${ }^{2}$, TIRTO APRIYANTO ${ }^{1}$, SYAHRUDDIN SYAHRUDDIN ${ }^{3}$}

${ }^{1}$ State University of Jakarta, Jakarta, Indonesia

${ }^{2}$ Bandung Institute of Technology, Bandung, Indonesia

${ }^{3}$ State University of Makassar, Makassar, Indonesia

\section{ABSTRACT}

Purpose. Cinnamon extract, which is the result of extraction from the bark of the genus Cinnamomum, belonging to the Lauraceae family, which grows in several continents, such as Asia, Australia, and America (South America), has made researchers enthusiastic to apply it as an athlete supplement. The purpose of this study was to examine whether 6-week daily consumption of cinnamon extract would affect anaerobic performance and reduce creatine kinase activity in badminton athletes.

Methods. Overall, 30 male badminton athletes (aged 19-21 years) were enrolled and recruited into the study; 15 participants were randomly assigned to the cinnamon group and the other group was a placebo group. Both groups underwent pre- and post-supplementation tests, which covered anaerobic capacity (20-m sprint test) and physical fitness (vertical jump, agility T-test, and sit-ups). A 5-minute rest was applied between the tests. Blood serum was analysed with the use of a chemistry auto-analyser (Cobas Mira S, USA) with the kinetic method to measure creatine kinase activity before and after the tests. Results. For the post-test creatine kinase activity, the results showed a significant main effect for group ( $p=0.022)$ and time $(p=0.018)$ and significant time $\times$ group interactions $(p=0.013)$. The T-test revealed a significant two-way interaction for time $\times$ group $(p=0.007)$. Additionally, there was a significant main effect for group $(p=0.025)$ and time $(p=0.003)$.

Conclusions. We demonstrated that cinnamon extract could reduce creatine kinase activity and improve agility T-test performance in badminton athletes.

Key words: creatine kinase, ergogenic, muscle damage, muscle function, performance

\section{Introduction}

With approximately 200 million adherents, badminton has become a racket sport that is popular in the world [1, 2]. In fact, badminton is used as a supporting activity to maintain health and for some it is a means to achieve individual or group objectives [3]. Events that involve competitions between countries such as the Olympics and Asian games are forums for such achievements [4]. Because of this, many coaches or athletes use a variety of the best ways to improve athletes' performance in order to ensure success in every competition. Badminton performance is characterized by intermittent activity of sporadic movements of moderate and high intensity [5]. Because the game is intermittent in its nature, it seems difficult to conduct investigations regarding the percentage of aerobic or anaerobic performance that occurs in badminton [6-8].

Previous literature has observed that during a badminton match, anaerobic processes play the biggest role in supplying energy, especially in the explosive movements of each rally, and the aerobic system provides about $65 \%$ of the energy needed for the continuous alternation of high intensity rallies, short recovery periods, and moderate intensity activities $[5,9,10]$. Fast movements with continuous change of direction and with lower intensity and short recovery periods

Correspondence address: Junaidi Junaidi, Universitas Negeri Jakarta, Rawamangun Muka Street, Pulo Gadung, East Jakarta City, 13220, Indonesia, e-mail: junaidi.sportmed@unj.ac.id

Received: August 1, 2019

Accepted for publication: January 2, 2020

Citation: Junaidi J, Apriantono T, Winata B, Hasan F, Apriyanto T, Syahruddin S. Effects of cinnamon extract supplementation on creatine kinase activity in badminton athletes. Hum Mov. 2020;21(4):102-110; doi: https://doi.org/10.5114/hm.2020.94196. 
are some of the characteristics observed in badminton $[11,12]$. Badminton belongs to the sports disciplines that require players to move quickly towards the projectile. Therefore, badminton athletes must avoid harmful factors, one of them being muscle damage [13]. It consists in muscles becoming stiff or sore, is caused by strenuous physical exercise, and becomes apparent within 24-72 hours after exercise [14].

Facing this problem, many coaches or athletes use supplements synthesized on technological lines (e.g. creatine) or natural and organic supplements during recovery from exercise. Many believe that natural, organic and synthesized supplementation will promote skeletal muscle anabolism and optimize restoration of muscle performance following exercise by reducing muscle damage or muscle soreness and thus improving the athlete's performance [15-17]. Because of this enthusiasm, some of the previous studies concentrated on the benefit of both natural and organic dietary supplements, such as carob [18] and Applephenon [19]. Additionally, Applephenon includes the highest concentration of apple polyphenol extract; it is obtained in an extraction process from unripe apples [19, 20]. Theoretically, polyphenols, which are antioxidants, present anti-fatigue activity, help supplement nutrition in athletes, and improve athletes' performance [21].

While many of the studies that observed natural and organic supplementation as antioxidant and anti-fatigue are relatively well documented, detailed data on natural and organic supplementation to reduce creatine kinase activity are still limited. In particular, in this context, cinnamon extract, which is the result of extraction from the bark of the genus Cinnamomum, belonging to the Lauraceae family, which grows in several continents, such as Asia, Australia, and America (South America), has made researchers enthusiastic to know and develop it as an athlete supplement because of its potential to enhance anaerobic power, strength, and endurance performance [22] or other benefits, such as antibacterial and antioxidant properties [23, 24]. For example, previous research has reported that consuming $500 \mathrm{mg}$ of cinnamon extract in powder form, with each creatine dose of $2 \mathrm{~g} / \mathrm{d}$ during the loading phase, followed by $500 \mathrm{~g} / \mathrm{d}$ in the maintenance phase can increase peak power during the Wingate test and peak speed during the sprint running test [22]. While these studies show ambiguous findings for muscle improvement after cinnamon extract intake, physiological measurements like creatine kinase activity are lacking. As such, the effects of cinnamon extract on insulin sensitivity, glucose transport up-regulation in skeletal muscles, and improving re- covery of athletes' muscle performance following strenuous physical exercise remain unclear.

To the authors' best knowledge, no available studies have reported the effect of cinnamon extract to enhance performance in athletes, especially in badminton athletes. Therefore, the aim of this study was to assess the effect of 6-week cinnamon extract consumption on anaerobic performance and creatine kinase activity in badminton athletes. We hypothesized that a 6-week period of cinnamon extract supplementation would significantly increase performance for anaerobic capacity and physical fitness and decrease creatine kinase activity.

\section{Material and methods}

\section{Participants}

Overall, 30 male badminton athletes (aged 19-21 years) studying at the Sports Science Faculty of State University of Jakarta were enrolled and recruited into the study on the basis of the following criteria: participation in national and international tournaments, training history of at least 15 hours per week, no history of smoking, no concomitant diseases and no use of any anti-inflammatory or anti-oxidant drugs within 1 month prior to the initial testing or during the experimental period.

Before pre-testing, a training team of 2 people conducted an investigation regarding each athlete's eligibility to participate in the study. Only those involved in a resistance training program could qualify. To maintain proper nutrition of all participants, a nutrition team of 2 people supervised the athletes' following the rules of a successive dietary agenda for 7 days prior to the study. The Bilnut 4 software package (SCDA Nutrisoft, France) was used to determine the diet and the food composition tables (Tunisian National Institute of Statistics) for all participants. The subjects' anthropometric data are shown in Table 1.

Table 1. Anthropometric data of participants

\begin{tabular}{lcc}
\hline Variables & $\begin{array}{c}\text { Cinnamon group* } \\
(\bar{x} \pm S D)\end{array}$ & $\begin{array}{c}\text { Placebo group** } \\
(\bar{x} \pm S D)\end{array}$ \\
\hline Age (years) & $19.7(0.70)$ & $19.6(0.72)$ \\
Weight $(\mathrm{kg})$ & $68.43(7.79)$ & $67.53(6.70)$ \\
Height $(\mathrm{cm})$ & $174.2(6.84)$ & $173.2(5.52)$ \\
BMI $\left(\mathrm{kg} / \mathrm{m}^{2}\right)$ & $22.53(2.01)$ & $22.48(1.75)$ \\
\hline
\end{tabular}

BMI - body mass index, $S D$ - standard deviation

* The cinnamon group received $500 \mathrm{mg}$ of cinnamon extract per day

** The placebo group received placebo juice 


\section{HUMAN MOVEMENT}

J. Junaidi et al., Effects of cinnamon extract on creatine kinase activity

\section{Experimental overview}

A double-blind, randomized, placebo-controlled, parallel group comparison trial was performed to examine whether cinnamon extract would enhance anaerobic performance and reduce creatine kinase activity in badminton athletes. Overall, 15 participants were randomly assigned to the cinnamon group (CG) and another 15 to the placebo group (PG). Both groups underwent pre- and post-supplementation tests, which covered anaerobic capacity (20-m sprint test) and physical fitness (vertical jump, agility T-test, and situps). Additionally, creatine kinase activity was determined before and 24 hours after the tests. All subjects practised the same training schedule during the 6 weeks of supplementation and they were familiarized with each exercise testing protocol separately. The research design is displayed in Figure 1.

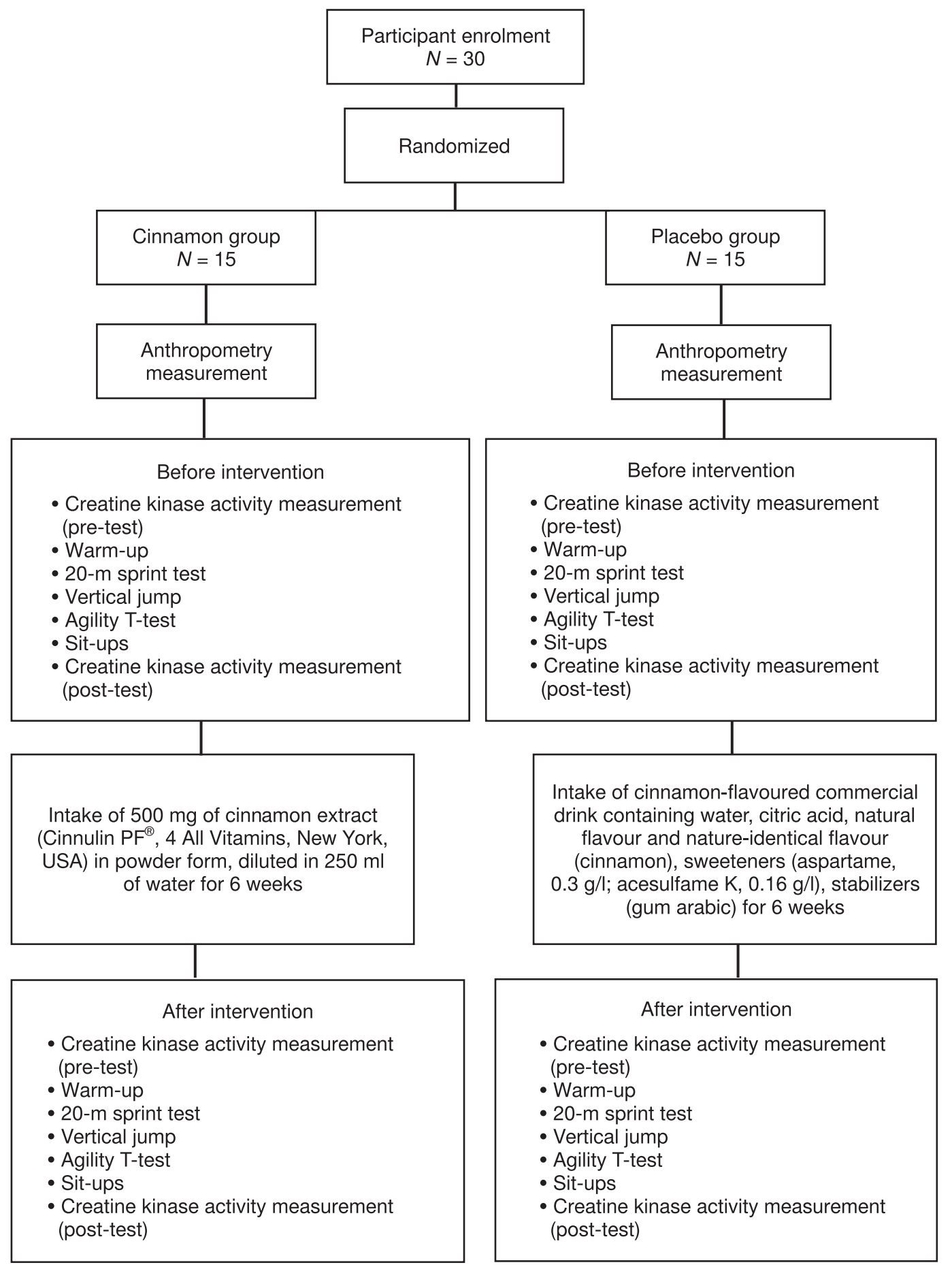

Figure 1. The research design 


\section{Experimental design}

After enrolment, the participants were randomized into 2 groups (CG and PG). Once daily, in the morning, at breakfast, during the 6 weeks of the study, CG received $500 \mathrm{mg}$ of cinnamon extract (Cinnulin $\mathrm{PF}^{\circledR}$, 4 All Vitamins, New York, USA) in powder form, diluted in $250 \mathrm{ml}$ of water, and PG received placebo juice, cinnamon-flavoured commercial drink containing water $(250 \mathrm{ml})$, citric acid, natural flavour and nature-identical flavour (cinnamon), sweeteners (aspartame, $0.3 \mathrm{~g} / \mathrm{l}$; acesulfame $\mathrm{K}, 0.16 \mathrm{~g} / \mathrm{l}$ ), stabilizers (gum arabic) and not containing anti-inflammatory or antioxidant substances. The doses of cinnamon extract and placebo were based on previous human studies [22].

One day before the study, we required all participants to have a light dinner (before 09:00 p.m.) and forbid them to consume food or drinks containing caffeine on the day of testing. Next morning at 08:00 a.m., anthropometric measurements were performed. The subjects wore minimal clothes and were barefoot. We used Omron HBF-375 Karada Scan Body Composition Scale to assess body weight and body fat percentage of all participants. A stadiometer with $0.1-\mathrm{cm}$ readability (Seca 214 Portable Stadiometer, Cardinal Health, Ohio, USA) was applied to measure body height. Body mass index was calculated as the ratio of body mass (kilograms) and body height (metres) squared.

After the anthropometric measurements, 5-ml samples of venous blood were collected from the median cubital vein to determine creatine kinase activity. A warm-up (6-minute jog at $6.8 \mathrm{~km} / \mathrm{h}$ ) was carried out before testing. The test began at 09:30 a.m. We measured the anaerobic capacity (20-m sprint test) and physical fitness (vertical jump, agility T-test, and situps). A 5-minute rest was applied between the tests. After the end of the last test, the participants were allowed to drink water ad libitum to prevent dehydration. All athletes also were required to sleep from 09:00 p.m. to 6:00 a.m. Furthermore, 24 hours after the testing, creatine kinase activity was measured.

To maintain the proper diet and training, the day after the post-test creatine kinase activity measurement, the study required all participants to live in their dormitories for 6 weeks and follow the same training sessions and nutrition guidelines provided by the training and nutrition teams during the experimental period. Furthermore, both groups practised exercise of the same variety and intensity during these 6 weeks. We provided the participants with training programs that included training sessions for technical skills and tactics. All subjects implemented a high-intensity interval training program consisting of shots technique (forehand and backhand) on both sides of the court (from side-line to side-line), with three series of two 2-minute repetitions at an intensity of $90 \%$ $(3 \times 2 \times 2 \mathrm{~min})$, with recoveries at 100 seconds between repetitions and 90 seconds between series. The training program was adopted from and based on a previous training program method [25]. The heart rate intensity was monitored with a test employing a Polar RS400 watch (Polar Electro Oy, Kempele, Finland).

All participants consumed their assigned juice supplementation at breakfast during the 6 -week period. A blinded research team member was assigned to oversee the provision of juice supplementation to the participants in accordance with their group assignment, and logs were also recorded to ensure compliance with juice supplementation consumption. Then, 24 hours after the last day of supplementation, postintervention testing was carried out identical to the pre-intervention one.

\section{Sprint test}

A 20-m 'maximal' sprint running was performed in the Jakarta Velodrome Athletic Stadium. At the initial test briefing, we instructed the participants to run as fast as possible. They were to stand up and get ready before the starting line (i.e. cone $\mathrm{A}$ ), as a sign of starting the $20-\mathrm{m}$ sprint. The first test administrator counted down to the start of the test $(3-2-1-\mathrm{GO})$. On the 'GO' signal, the participants ran at the maximum speed possible towards the finish line (i.e. cone B). As soon as the participant crossed the $20-\mathrm{m}$ line, the second test administrator (standing on the end line) shouted 'STOP'. The running time of the sprints were recorded by using a beam photocell system (Microgate, Bolzano, Italy).

\section{Physical fitness}

The vertical jump test was administered in accordance with the guidelines proposed by Monks et al. [26]. The results were measured with a device by Vertec Polymers (Houston, USA). Vertec is a construction with horizontal vanes located with 1 -inch increments. The lowest vane was adjusted to be placed at the point of the longest finger with the arm fully expanded and both feet resting on the ground; the jump height was simply determined by the highest vane reached. The participants jumped vertically as high as possible, with their maximum effort, using both arms and legs to 
assist in projecting the body upwards. A practice jump was performed to familiarize the athletes with the test before the recorded jumps started. The mean of 3 attempts was recorded.

The agility T-test, in the version standardized in previous literature [27], was performed to assess speed and agility in the badminton athletes, including forward, lateral, and backward running. Four cones were set out ( 5 meters apart). The participant started at cone $\mathrm{A}$. The administrator counted down to begin the test (3-2 - 1-START). Two administrators pressed the start button on a stopwatch when they heard the 'START' signal; the participants ran at the maximum speed possible to cone $B$ and touched the cone with their hands. As soon as they touched cone B, they immediately turned left, shuffled sideways to cone C, and also touched the cone with their hands. Then, the participants moved to the right, toward cone $\mathrm{D}$, and touched the cone with the right hand. They then shuffled back to cone B, touching it with the left hand, and then ran backwards to cone A. The administrators pressed the stop button on the stopwatch when the athlete passed cone A. The trial was not counted if the participant crossed one foot in front of the other while shuffling, failed to touch the base of the cones, or failed to face forward throughout the test. The best time of 2 successful trials was recorded to the nearest $0.1 \mathrm{~s}$. All times were recorded by using a stopwatch (Seiko Stopwatch S23601P).

The sit-up test in a 1-minute period was used to measure the strength or muscle endurance [28]. All participants lay on a flat mattress with clean surface, with knees flexed at $90^{\circ}$; a partner assisted by anchoring the feet to the ground. With arms crossed over the chest, the participant elevated the trunk in a smooth motion so that it created an imaginary V-shape with their thighs. The subject's trunk was required to touch the floor shortly after creating the imaginary V-shape.

\section{Blood sample analyses}

Blood samples were collected from the median cubital vein $(5 \mathrm{ml})$. They were centrifuged at $1700 \mathrm{~g}$ for 10 minutes at $4^{\circ} \mathrm{C}$. Blood serum was analysed with the use of a chemistry auto-analyser (Cobas Mira S, USA) with the kinetic method, in accordance with the rules of the International Federation of Clinical Chemistry and the German Society for Clinical Chemistry, for the determination of creatine kinase activity. For the analysis, we mixed reagent (A) creatine kinase liquid, vol. $=40 / 80 \mathrm{ml}$ (consisting of Good's buffer $125 \mathrm{mmol} / \mathrm{l}$, magnesium acetate $12 \mathrm{mmol} / \mathrm{l}$, EDTA $2 \mathrm{mmol} / \mathrm{l}$,
D-glucose $25 \mathrm{mmol} / \mathrm{l}, \mathrm{N}$-accetyl-L-cysteine $25 \mathrm{mmol} / \mathrm{l}$, NADP $2.5 \mathrm{mmol} / \mathrm{l}$, and HK-hexokinase $\geq 6500 \mathrm{U} / \mathrm{l}$ ), with reagent $(B)$ creatine kinase liquid, vol. $=10 / 20 \mathrm{ml}$ (consisting of ADP $15 \mathrm{mmol} / \mathrm{l}$, AMP $25 \mathrm{mmol} / \mathrm{l}$, di-adenosine 5-phosphate $103 \mu \mathrm{mol} / \mathrm{l}, \mathrm{G}-6-\mathrm{PDH} \geq 8800 \mathrm{U} / \mathrm{l}$, and creatine phosphate $250 \mathrm{mmol} / \mathrm{l}$ ) with $\lambda=340 \mathrm{~nm}$ at the temperature of $37^{\circ} \mathrm{C}$.

\section{Statistical analysis}

The statistical analysis tests were performed with the SPSS software, V.21.0. Normal distribution of the sample was checked by using the Shapiro-Wilk test. A 2 (group: CG and PG) $\times 2$ (time: pre-, post-) repeated measures analysis of variance (ANOVA) was calculated for each parameter. To reveal the differences between pre- and post-supplementation results in each group, we used the independent $t$-test. The $95 \%$ confidence interval and percentage changes were calculated. Statistical significance was accepted at $p<0.05$.

\section{Ethical approval}

The research related to human use has complied with all the relevant national regulations and institutional policies, has followed the tenets of the Declaration of Helsinki, and has been approved by the ethics committee of the Federation of Sports Medicine, State University of Jakarta (350/UN39.14/PR.05/2018).

\section{Informed consent}

Informed consent has been obtained from all individuals included in this study.

\section{Results}

Table 2 displays mean and $S D$ values, as well as percentage changes for the 20-m sprint, vertical-jump, T-test, sit-ups, and creatine kinase activity before and after supplementation in CG and PG.

\section{Creatine kinase activity}

As presented in Table 3, the independent $t$-test revealed no significant differences between pre- and post-intervention pre-test creatine kinase activity in CG $(p=0.667)$ or PG $(p=0.415)$. Additionally, ANOVA showed no significant time $\times$ group interactions $(p=0.986)$. The statistical analysis detected no significant main effect for group $(p=0.456)$ or time $(p=0.623)$. Furthermore, the independent $t$-test proved significant changes between pre- and post-intervention post-test creatine kinase activity in CG $(p=0.001)$. Specifically, 
Table 2. Effects of cinnamon supplementation on creatine kinase, 20-m sprint, vertical jump, agility T-test, and sit-ups

\begin{tabular}{|c|c|c|c|c|c|c|c|c|c|c|c|}
\hline \multirow[b]{2}{*}{ Variables } & \multicolumn{4}{|c|}{ Cinnamon group $^{1}$} & \multicolumn{4}{|c|}{ Placebo group $^{2}$} & \multicolumn{3}{|c|}{$p^{\mathrm{b}}$} \\
\hline & $\begin{array}{c}\text { Pre- } \\
\text { intervention } \\
(\bar{x} \pm S D)\end{array}$ & $\begin{array}{c}\text { Post- } \\
\text { intervention } \\
(\bar{x} \pm S \mathrm{D})\end{array}$ & $\Delta \%$ & $p^{\mathrm{a}}$ & $\begin{array}{c}\text { Pre- } \\
\text { intervention } \\
(\bar{x} \pm S D)\end{array}$ & $\begin{array}{c}\text { Post- } \\
\text { intervention } \\
(\bar{x} \pm S D)\end{array}$ & $\Delta \%$ & $p^{\mathrm{a}}$ & Group & Time & $\begin{array}{l}\text { Group } \\
\times \text { time }\end{array}$ \\
\hline Pre-test CK activity (U/l) & $169.13 \pm 19.15$ & $171.13 \pm 14.95$ & 1.18 & 0.667 & $166.27 \pm 13.17$ & $168.13 \pm 12.36$ & 1.12 & 0.415 & 0.456 & 0.623 & 0.986 \\
\hline 20-m sprint (s) & $4.17 \pm 0.29$ & $3.97 \pm 0.49$ & -4.8 & $0.033^{*}$ & $3.83 \pm 0.43$ & $3.91 \pm 0.60$ & 2.26 & 0.382 & 0.110 & 0.642 & 0.241 \\
\hline Vertical-jump (inch) & $17.27 \pm 1.62$ & $18.07 \pm 1.16$ & 4.63 & $0.017^{*}$ & $17.40 \pm 2.03$ & $17.47 \pm 2.10$ & 0.38 & 0.774 & 0.611 & 0.347 & 0.425 \\
\hline Agility T-test (s) & $13.11 \pm 0.62$ & $11.91 \pm 0.84$ & -9.1 & $0.001^{*}$ & $12.09 \pm 0.74$ & $12.01 \pm 0.87$ & -0.61 & 0.563 & $0.025^{*}$ & $0.003^{*}$ & $0.007^{*}$ \\
\hline Sit-ups (repetitions) & $41.67 \pm 2.58$ & $42.27 \pm 2.37$ & 1.44 & 0.167 & $41.67 \pm 2.58$ & $41.80 \pm 2.86$ & 0.32 & 0.744 & 0.730 & 0.588 & 0.730 \\
\hline Post-test CK activity (U/l) & $335.20 \pm 20.66$ & $311.20 \pm 23.55$ & -7.16 & $0.001^{*}$ & $334.27 \pm 14.64$ & $334.80 \pm 13.66$ & 0.16 & 0.823 & $0.022^{*}$ & $0.018^{*}$ & $0.013^{*}$ \\
\hline
\end{tabular}

$S D$ - standard deviation, CK - creatine kinase

${ }^{1}$ The cinnamon group received $500 \mathrm{mg}$ of cinnamon extract per day

${ }^{2}$ The placebo group received placebo juice

${ }^{\text {a } I n d e p e n d e n t ~} t$-test

b $2 \times 2$ repeated measures ANOVA

* Statistically significant differences between CG and PG $(p<0.05)$

Table 3. Specific changes in creatine kinase, 20-m sprint, vertical jump, agility T-test, and sit-up measures in the cinnamon and placebo groups

\begin{tabular}{|c|c|c|c|c|c|c|c|c|c|c|}
\hline \multirow{2}{*}{ Groups } & \multirow{2}{*}{ Variables } & \multirow{2}{*}{ Time } & \multirow{2}{*}{ Mean } & \multirow{2}{*}{$\begin{array}{l}\text { Standard } \\
\text { deviation }\end{array}$} & \multirow{2}{*}{$\begin{array}{l}\text { Standard } \\
\text { error mean }\end{array}$} & \multicolumn{2}{|c|}{$\begin{array}{l}95 \% \text { confidence interval } \\
\text { of the difference }\end{array}$} & \multirow[t]{2}{*}{$t$} & \multirow[t]{2}{*}{$d f$} & \multirow[t]{2}{*}{$p$} \\
\hline & & & & & & Lower & Upper & & & \\
\hline Cinnamon & Pre-test CK activity (U/l) & Pre-post & -2.000 & 17.610 & 4.547 & -11.752 & 7.752 & -0.440 & 14 & 0.667 \\
\hline Placebo & Pre-test CK activity (U/l) & Pre-post & -1.866 & 8.609 & 2.222 & -6.634 & 2.901 & -0.840 & 14 & 0.415 \\
\hline Cinnamon & 20-m sprint (s) & Pre-post & 0.200 & 0.327 & 0.084 & 0.018 & 0.381 & 2.366 & 14 & 0.033 \\
\hline Placebo & 20-m sprint (s) & Pre-post & -0.086 & 0.372 & 0.096 & -0.292 & 0.119 & -0.902 & 14 & 0.382 \\
\hline Cinnamon & Vertical jump (inch) & Pre-post & -0.800 & 1.146 & 0.296 & -1.434 & -0.165 & -2.703 & 14 & $0.017^{*}$ \\
\hline Placebo & Vertical jump (inch) & Pre-post & -0.066 & 0.883 & 0.228 & -0.556 & 0.422 & -0.292 & 14 & 0.774 \\
\hline Cinnamon & Agility T-test (s) & Pre-post & 1.193 & 0.872 & 0.225 & 0.709 & 1.676 & 5.294 & 14 & $0.001^{*}$ \\
\hline Placebo & Agility T-test (s) & Pre-post & 0.073 & 0.478 & 0.123 & -0.191 & 0.338 & 0.593 & 14 & 0.563 \\
\hline Cinnamon & Sit-ups (repetitions) & Pre-post & -0.600 & 1.594 & 0.411 & -1.483 & 0.283 & -1.457 & 14 & 0.167 \\
\hline Placebo & Sit-ups (repetitions) & Pre-post & -0.133 & 1.552 & 0.400 & -0.992 & 0.726 & -0.333 & 14 & 0.744 \\
\hline Cinnamon & Post-test CK activity (U/l) & Pre-post & 24.000 & 14.599 & 3.769 & 15.915 & 32.084 & 6.367 & 14 & $0.001^{*}$ \\
\hline Placebo & Post-test CK activity (U/l) & Pre-post & -0.533 & 9.054 & 2.337 & -5.547 & 4.480 & -0.228 & 14 & 0.823 \\
\hline
\end{tabular}

CK - creatine kinase

Statistical analysis with independent $t$-test

* Statistically significant differences between pre- and post-intervention tests $(p<0.05)$

for the post-test creatine kinase activity, there was a significant main effect for group $(p=0.022)$ and time $(p=0.018)$, as well as significant time $\times$ group interactions $(p=0.013)$.

\section{0-m sprint}

Regarding the 20-m sprint performance, the results showed no statistically significant differences for time ( $p=0.642)$ or group $(p=0.110)$ main effects or time $\times$ group interaction effects $(p=0.241)$. However, the independent $t$-test revealed significant changes between pre- and post-intervention results in CG ( $p=0.033)$.

\section{Vertical jump}

There was a significant change in the independent $t$-test only in CG $(p=0.017)$. Furthermore, ANOVA revealed no significant main effects of time $(p=0.347)$ or group ( $p=0.611)$ and no significant time $\times$ group interactions $(p=0.425)$ for the vertical jump test.

\section{Agility T-test}

For the T-test, there was a significant two-way interaction for time $\times$ group $(p=0.007)$. Additionally, a significant main effect was observed for group $(p=$ 
$0.025)$ and time ( $p=0.003)$. Specifically, the independent $t$-test also revealed significant changes between pre- and post-intervention results in CG ( $p=0.001)$ for the T-test.

\section{Sit-ups}

The statistical analyses proved no significant main effects of time $(p=0.588)$ or group $(p=0.730)$ and no significant time $\times$ group interactions $(p=0.730)$ for the sit-up test. The independent $t$-test also revealed no significant change between pre- and post-intervention results in PG $(p=0.730)$ for the sit-up test.

\section{Discussion}

The purpose of the study was to assess the effect of a daily intake of $500 \mathrm{mg}$ of cinnamon extract in powder form, diluted in $250 \mathrm{ml}$ of water, on reducing creatine kinase activity and enhancing performance in badminton athletes. In line with our prior hypothesis, we stated that the $500 \mathrm{mg}$ of cinnamon extract significantly decreased creatine kinase activity and enhanced performance in the agility T-test among badminton players. This result is of significant importance because supplementation to reduce muscle damage is crucial in intermittent characteristics sports such as badminton. Besides, to the authors' best knowledge, this is the first study to assess the effects of cinnamon extract supplementation on the basis of creatine kinase activity and anaerobic performance in badminton athletes.

As reported in the results of the present study, CG demonstrated significantly reduced creatine kinase activity after 6 weeks of supplementation with cinnamon extract. This can be noticed in the statistical analysis that revealed a significant main effect for group $(p=0.022)$ and time $(p=0.018)$, as well as significant time $\times$ group interactions $(p=0.013)$, indicating that creatine kinase activity decreased in CG 24 hours after the tests. The explanation for these phenomena can be offered by a previous study with similar characteristic functions of cinnamon extract; Fayaz et al. [29], in their in vivo research with ovariectomized rats, found that cinnamon supplements combined with highendurance training for 12 weeks could efficiently reduce insulin resistance and metabolic dysfunction. We may speculate that cinnamon extract has been shown to improve insulin sensitivity and up-regulate glucose transport in skeletal muscles owing to enhanced phosphatidylinositol 3-kinase signalling (PI3K) through the insulin receptor and insulin receptor sub- strate (IRS-1) signalling pathways [22]. Therefore, these insulin-like effects may stimulate CreaT1 and prevent an increase in creatine kinase activity [30].

The results of this study support a previous study which found that cinnamon extract could enhance performance. Islam et al. [22] explained that $500 \mathrm{mg}$ of cinnamon extract diluted in $500 \mathrm{ml}$ of water and consumed once daily for 3 weeks could be effective as a natural supplementation to enhance anaerobic power, strength, and endurance performance. Despite the differences between the two studies, the similar results in our study may have been caused by the insulinogenic effects of cinnamon extract. However, since we did not measure blood glucose concentration, further studies on the relationship between creatine kinase and blood glucose are needed to better elucidate these aspects in badminton players.

In addition, we also investigated the effects of cinnamon extract on agility T-test performance as specifically relevant to badminton and to the characteristics of each player in every match or training. This is also in accordance with the explanation by Loureiro et al. [31] that agility is the main physical ability that must be possessed by every badminton player to achieve success in badminton modalities. Furthermore, in realmatch situations, each player is required to have the ability of fast movements to each side of the field in reaching the shuttlecock directed by the opposing player [32]. Therefore, agility improvement is one of the main goals for players to increase their performance on the court [31]. At the end of our protocol, we observed significant improvements in the agility T-test in CG but not in PG. However, finding comparisons with literature regarding the effect cinnamon extract on agility T-test performance was difficult. Despite the benefit of cinnamon extract that provides insulinogenic effects, post-activation potentiation (PAP) is another possible reason that causes an increase in the agility T-test. Previous studies explained that the performance of jumps during the game would increase in long jumps (2-legged rebound vertical jumps) with plyometric training executed 3 minutes before each attempt [33]. Specifically, the acute increase in long-jump performance after the conditioning activity may be explainable by the phenomenon of PAP [34].

The similarity of the results shown in this study may have been caused by the PAP effects from vertical jump. Although no measurements were done to identify the mechanisms causing PAP in the current study, we may speculate that the increasing performance of agility T-test was generated by the 5 minutes after vertical-jump attempt. Furthermore, previous litera- 
ture argues that PAP is manifested by an increased rate of force development and may be induced by 2 main mechanisms: phosphorylation of regulatory myosin light chains that renders the actin-myosin interaction more sensitive to calcium and causes conformational changes of the myosin head, or increased recruitment of high-order motor units through a decreased threshold of activation for the fast-twitch motoneurons $[34,35]$.

We realize that there are still some limitations in this study. The physical, role-related, and emotional functioning, and the participants' lifestyle differences are some aspects that we cannot control, and are likely to be influential in the results of this study. Secondly, the lack of any repeated efforts may have attenuated the effects of cinnamon extract supplementation on anaerobic performance. To address the limitations of this study, we expect that further research can involve a large cohort and more control regarding nutrition intake, exercise programs, and the psychology of participants during the testing period to ensure the potential effect of cinnamon extract on creatine kinase activity and athletes' performance.

\section{Conclusions}

We demonstrated that cinnamon extract significantly decreased creatine kinase activity and enhanced performance in agility T-test among badminton players. Future studies are needed to explain the related phenomena behind the benefits of cinnamon extract such as improving athletes' performance and decreasing creatine kinase activity.

\section{Acknowledgments}

The authors would like to thank State University of Jakarta and Bandung Institute of Technology for their help and provision of infrastructure in this research. The study did not receive any financial support.

\section{Disclosure statement}

No author has any financial interest or received any financial benefit from this research.

\section{Conflict of interest}

The authors state no conflict of interest.

\section{References}

1. Kwan M, Cheng CL, Tang WT, Rasmussen J. Measurement of badminton racket deflection during a stroke. Sports Eng. 2010;12(3):143-153; doi: 10.1007/s12283010-0040-5.
2. Lo D, Stark K. Sports performance series: the badminton overhead shot. Natl Strength Cond J. 1991;13(5):613; doi: 10.1519/0744-0049(1991)013<0006:tbos $>2$. 3.co;2.

3. Bravo-Sánchez A, Abián-Vicén J, Jiménez F, Abián P. Influence of badminton practice on calcaneal bone stiffness and plantar pressure. Phys Sportsmed. 2020;48(1): 98-104; doi: 10.1080/00913847.2019.1635050.

4. Feizabadi MS, Khabiri M, Hamidi M. The relationship between the success of countries at the Guangzhou 2010 Summer Asian Games and demo-economic factors. Procedia Soc Behav Sci. 2013;82:369-374; doi: 10.1016/j.sbspro.2013.06.277.

5. Rampichini S, Limonta E, Pugliese L, Cè E, Bisconti AV, Gianfelici A, et al. Heart rate and pulmonary oxygen uptake response in professional badminton players: comparison between on-court game simulation and laboratory exercise testing. Eur J Appl Physiol. 2018; 118(11):2339-2347; doi: 10.1007/s00421-018-3960-6.

6. Fuchs M, Faude O, Wegmann M, Meyer T. Critical evaluation of a badminton-specific endurance test. Int $\mathrm{J}$ Sport Physiol Perform. 2014;9(2):249-255; doi: 10.1123/ ijspp.2012-0387.

7. Phomsoupha M, Laffaye G. The science of badminton: game characteristics, anthropometry, physiology, visual fitness and biomechanics. Sports Med. 2015; 45(4):473-495; doi: 10.1007/s40279-014-0287-2.

8. Lees A. Science and the major racket sports: a review. J Sports Sci. 2003;21(9):707-732; doi: 10.1080/ 0264041031000140275.

9. Faude O, Meyer T, Rosenberger F, Fries M, Huber G, Kindermann W. Physiological characteristics of badminton match play. Eur J Appl Physiol. 2007;100(4): 479-485; doi: 10.1007/s00421-007-0441-8.

10. Tomlin DL, Wenger HA. The relationship between aerobic fitness and recovery from high intensity intermittent exercise. Sports Med. 2001;31(1):1-11; doi: 10.2165/ 00007256-200131010-00001.

11. Kwan M, Andersen MS, Zee M, Rasmussen J. Dynamic model of a badminton stroke. In: Estivalet M, Brisson P (eds.), The engineering of sport 7. Paris: Springer; 2008; 563-571.

12. Deka P, Berg K, Harder J, Batelaan H, McGrath M. Oxygen cost and physiological responses of recreational badminton match play. J Sports Med Phys Fitness. 2017;57(6):760-765; doi: 10.23736/S0022-4707.16. 06319-2.

13. Pasiakos SM, Lieberman HR, McLellan TM. Effects of protein supplements on muscle damage, soreness and recovery of muscle function and physical performance: a systematic review. Sports Med. 2014;44(5): 655-670; doi: 10.1007/s40279-013-0137-7.

14. Baumert P, Lake MJ, Stewart CE, Drust B, Erskine RM. Genetic variation and exercise-induced muscle damage: implications for athletic performance, injury and ageing. Eur J Appl Physiol. 2016;116(9):1595-1625; doi: 10.1007/s00421-016-3411-1. 
15. Braun H, Koehler K, Geyer H, Kleiner J, Mester J, Schanzer W. Dietary supplement use among elite young German athletes. Int J Sport Nutr Exerc Metab. 2009; 19(1):97-109; doi: 10.1123/ijsnem.19.1.97.

16. Herbold NH, Visconti BK, Frates S, Bandini L. Traditional and nontraditional supplement use by collegiate female varsity athletes. Int J Sport Nutr Exerc Metab. 2004;14(5):586-593; doi: 10.1123/ijsnem.14.5.586.

17. Amato A, Sacco A, Macchiarella A, Contrò V, Sabatino E, Galassi C, et al. Influence of nutrition and genetics on performance: a pilot study in a group of gymnasts. Hum Mov. 2017;18(3):12-16; doi: 10.1515/humo-20170029.

18. Gaamouri N, Zouhal H, Hammami M, Hackney AC, Abderrahman AB, Saeidi A, et al. Effects of polyphenol (carob) supplementation on body composition and aerobic capacity in taekwondo athletes. Physiol Behav. 2019;205:22-28; doi: 10.1016/j.physbeh.2019.03.003.

19. Ataka S, Tanaka M, Nozaki S, Mizuma H, Mizuno K, Tahara T, et al. Effects of Applephenon ${ }^{\circledR}$ and ascorbic acid on physical fatigue. Nutrition. 2007;23(5):419423; doi: 10.1016/j.nut.2007.03.002.

20. Aprikian O, Busserolles J, Manach C, Mazur A, Morand $\mathrm{C}$, Davicco MJ, et al. Lyophilized apple counteracts the development of hypercholesterolemia, oxidative stress, and renal dysfunction in obese Zucker rats. J Nutr. 2002;132(7):1969-1976; doi: 10.1093/jn/132.7. 1969.

21. Kawatra P, Rajagopalan R. Cinnamon: mystic powers of a minute ingredient. Pharmacognosy Res. 2015; 7(Suppl. 1):S1-S6; doi: 10.4103/0974-8490.157990.

22. Islam H, Yorgason NJ, Hazell TJ. Creatine co-ingestion with carbohydrate or cinnamon extract provides no added benefit to anaerobic performance. Eur J Sport Sci.2016;16(6):685-693; doi:10.1080/17461391.2015. 1071877.

23. Archer AW. Determination of cinnamaldehyde, coumarin and cinnamyl alcohol in cinnamon and cassia by high-performance liquid chromatography. J Chromatogr. 1988;447:272-276; doi: 10.1016/0021-9673(88) 90035-0.

24. Kumar K, Issac A, Ninan E, Kuttan R, Maliakel B. Enhanced anti-diabetic activity of polyphenol-rich decoumarinated extracts of Cinnamomum cassia. J Funct Foods. 2014;10:54-64; doi: 10.1016/j.jff.2014.05.008.

25. Suárez Rodríguez D, Del Valle Soto M. A study of intensity, fatigue and precision in two specific interval trainings in young tennis players: high-intensity interval training versus intermittent interval training. BMJ Open Sport Exerc Med. 2017;3(1):e000250; doi: 10.1136/bmjsem-2017-000250.

26. Monks L, Seo MW, Kim HB, Jung HC, Song JK. High-intensity interval training and athletic performance in Taekwondo athletes. J Sports Med Phys Fitness. 2017;57(10):1252-1260; doi: 10.23736/S00224707.17.06853-0.

27. Miller MG, Herniman JJ, Ricard MD, Cheatham CC, Michael TJ. The effects of a 6 -week plyometric training program on agility. J Sports Sci Med. 2006;5(3):459465.

28. Morris CE, Wessel PA, Tinius RA, Schafer MA, Maples JM. Validity of activity trackers in estimating energy expenditure during high-intensity functional training. Res Q Exerc Sport. 2019;90(3):377-384; doi: 10.1080/02701367.2019.1603989.

29. Fayaz E, Damirchi A, Zebardast N, Babaei P. Cinnamon extract combined with high-intensity endurance training alleviates metabolic syndrome via non-canonical WNT signaling. Nutrition. 2019;65:173-178; doi: 10.1016/j.nut.2019.03.009.

30. Op 't Eijnde B, Ursø B, Richter EA, Greenhaff PL, Hespel P. Effect of oral creatine supplementation on human muscle GLUT4 protein content after immobilization. Diabetes. 2001;50(1):18-23; doi: 10.2337/ diabetes.50.1.18.

31. De França Bahia Loureiro L Jr, Costa Dias MO, Cremasco FC, da Silva MG, de Freitas PB. Assessment of specificity of the Badcamp agility test for badminton players. J Hum Kinet. 2017;57:191-198; doi: 10.1515/ hukin-2017-0060.

32. Hussain I, Bari MA. Kinematical analysis of forehand and backhand smash in badminton. Innov Syst Des Eng. 2011;2(7):20-26.

33. Bogdanis GC, Tsoukos A, Veligekas P. Improvement of long-jump performance during competition using a plyometric exercise. Int J Sports Physiol Perform. 2017;12(2):235-240; doi: 10.1123/ijspp.2016-0116.

34. Farrow D, Young W, Bruce L. The development of a test of reactive agility for netball: a new methodology. J Sci Med Sport. 2005;8(1):52-60; doi: 10.1016/S1440-2440 (05)80024-6.

35. Tillin NA, Bishop D. Factors modulating post-activation potentiation and its effect on performance of subsequent explosive activities. Sports Med. 2009;39(2): 147-166; doi: 10.2165/00007256-200939020-00004. 